\title{
Requirements and System Architecture of Tour Planning Support for Local Revitalization
}

\author{
Motoi Iwashita *, Yutaka Shirai *
}

\begin{abstract}
An aging society has evidently had effects such as the recent depopulation, the increase in abandoned farmland, and so on in Japan. Therefore, realizing local revitalization is of the utmost importance, and there are many countermeasures in place to guard against the effects of an aging society. In particular, tourism is one of the most effective countermeasures, and each region tries to introduce it with a combination of local resources. Although it is common knowledge that local revitalization has a positive effect in an affected area, it is difficult to maintain revitalization activities over the long term. Therefore, this paper discusses a framework for maintaining local revitalization based on the classification of sightseeing resources and a chain of them. Moreover, tour planning is essential in order to stimulate tourism and to maintain a supply of sightseeing resources. Therefore, the requirements and system architecture for tour planning support are introduced as the first step.
\end{abstract}

Keywords: Tour planning, local revitalization, system architecture, sightseeing chain management.

\section{Introduction}

According to the population census of Japan, the Japanese population will decrease to 90 million in 2050 [1]. The birth rate in Japan has been in decline for the past decade, which has accelerated the aging of the population. New issues are emerging in every field, such as pension, medical care, standard of living, employment, and so on. Primary industries especially are seriously affected by the aging of society. For example, because of the decrease in the number of laborers, farmers have difficulty managing their own farmlands; the total area of abandoned farmlands has recently increased. About 420 kilo hectare farmland was lost due to abandonment in 2015 [2]. This phenomenon is caused by an influx of youth to cities and aging society. Other evidence includes the many vacant stores and deserted streets, some even in the center of cities. Moreover, this downward trend interrupts the provision of public transportation such as train and bus for local residents.

\footnotetext{
* Chiba Institute of Technology, Chiba, Japan
} 
From the perspective of facility management, abandoned farmlands may be in danger of wildfires. Moreover, if wastelands grow, the illegal dumping of waste will unfortunately increase. As for vacant stores, abandonment may also give rise to an increase in crime because people feel free of the watchfulness of the public eye in such situations. Therefore, addressing the management of those facilities is one of the most important and urgent matters in local areas.

The problem of an aging society can occur almost anywhere, and rural areas experience the worst consequences from this problem. Cities lure young people with jobs and recreational activities, while rural areas are less fascinating and have fewer jobs for youths. Therefore, many rural areas need local revitalization; some have even planned and executed revitalization strategies. People in rural areas find ways to increase the number of visitors, such as building sightseeing spots, creating special cuisine, planning festivals, and so on. Some efforts have been successful, but it is difficult to maintain a steady number of visitors. Although there are many effective measures to revitalize local areas, in this paper we focus on the support for tourism as one measure for local revitalization. One of the key solutions is to discover the factors involved in continuous revitalization.

Our study aims to propose continuous support systems based on tourism in order to revitalize local areas. Because few people know about local resources, it is helpful to give people further information about these resources. Doing so increases interest and tourism. Therefore, a tour planning support tool or system is needed to make self-planning easy. This paper first focuses on the requirements of tourism, and constructs a framework for a sustainable system based on the sightseeing resources. It is very difficult for strangers to make an itinerary of unfamiliar places efficiently. Therefore, a tour planning support system architecture from basic planning to the travel stage is proposed as a measure. Section 2 introduces related studies on local revitalization from the perspective of tourism and tour planning/recommendation system. Section 3 is devoted to the requirements of visitors, taking the Oga peninsula area as an example and giving a framework for a sustainable local revitalization system. In Section 4, a framework for a tour planning support system is extracted and formalized. Section 5 gives an entire system and application architecture for a tour planning support system. And Section 6 concludes the paper.

\section{Related works}

In the agricultural field, many revitalization trials for abandoned farmlands have been conducted nationwide. Even in Akita Prefecture, some countermeasures were executed. Many regions in Akita Prefecture have a high population-aging rate of over $40 \%$. However, they continue trying to grow local resources such as buckwheat noodles and vegetables. The group that leads countermeasures to revitalize the situation of an area is of importance. It deeply depends on the area itself. Farming corporations are the ones responsible for undertaking countermeasures in some regions, while volunteer groups do that in other regions. However, it is very difficult to continue with the revitalization of an area for a long time if we only take agricultural crops and abandoned farmlands into account.

There are many measures for revitalization that focus on tourism. Departure-based tourism, in which a travel agency in a city determines a schedule and makes the necessary arrangements for visitors, was a major type of tourism in the past. However, there are now many types of travelers. They tend to explore according to their own interests, such as scenery, food, new experiences, and so on. Departure-based tourism has certain limitations that prevent people from fulfilling 
their interests. Therefore, destination-based tourism, in which people from the local area make plans and promote their area to visitors, has become popular. There have been several studies in this field. A knowledge management system for supporting endogenous tourism has recently been developed [3]. This system stores historical information such as old stories from tour guides, which it provides to visitors. Because using a car is necessary for transportation in local regions, there are several Michinoeki roadside stations in Japan. Previous studies have explored the functions of a roadside station [4] and have indicated the importance of its four functions: break function, sending information function, local communication function, and disaster prevention function. The features of peninsula sightseeing are discussed in [5], in which natural landscape and rich agricultural and marine resources are described. The prevalence of experienced-based tourism is discussed in [6].

It is common knowledge that local revitalization has a positive effect on the residents of an affected area, and on the nation. However, after implementing revitalization measures, it is very difficult to maintain activities over the long term. The application of Soft System Methodology (SSM) [7] in this field can help solve the problem. Our previous study aims to implement supply management for sightseeing resources using SSM [8]. In this supply management, the importance of work production using local resources is discussed for local revitalization.

Research has evolved to combine departure-based and destination-based tourism [9]. A design tool for individual visitors has been developed as a self-planning service. Making an efficient itinerary in an unfamiliar place is generally difficult for visitors. There have been many studies done of Tourism Recommender Systems (TRSes) [10] for use in visiting unfamiliar places, which we survey. This research classifies the targets into whole areas, single sightseeing spots, and combinations of spots. Moreover, it classifies approaches into content-based filtering, collaborative filtering, and demographic approaches. The analysis of TRSes from the viewpoint of social sciences, not from the technological perspective, leads to the conclusion that intelligent systems are necessary in the tourism domain [11]. The functionalities required for TRSes is discussed [12]. Route planning is one of the major tour support functionalities, and its system overview is discussed [13]. The technology that allows the system to automatically make tour plans, recommend them to visitors, and revise the plans interactively, is introduced [14]. Such a trial system may be implemented in the near future. Although artificial intelligence effectively recommends based on a visitor's preference, the scope of the recommendation is limited; broad recommendations are difficult to achieve. Therefore, it is necessary to construct a more flexible and interactive system architecture that is easy to expand if conditions are added.

\section{Points of sustainable requirements}

In our previous study about local revitalization [8], we took Oga City in Akita Prefecture as an example because of its aging population. The population of Oga city was about 30,000 in 2015; it is gradually decreasing. The population composition of Oga city in 2015 with respect to age is shown in Figure 1. The population of the age group 60 to 64 years is the largest regardless of gender differences. Moreover, the percentage of population over 60 years old is very high. The aging population is definitely increasing these days. 


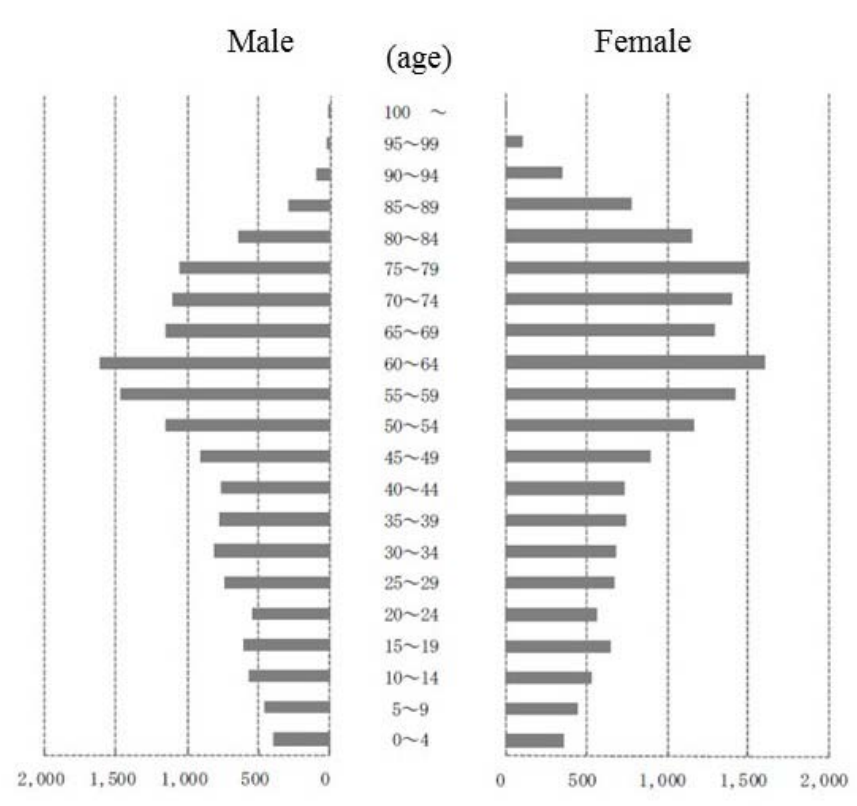

Figure 1: Population in Oga city (2015)

\subsection{Feature of Oga city}

A SWOT analysis was conducted in order to understand the position of the community people. The strengths, weaknesses, opportunities, and threats of the Oga area are listed, considering "lack of workforce" and "lack of local industry" as obtained by Rich Picture.

S (Strengths):

- $\quad$ Rich and changeful land features with mountain and sea (strange rocks, ragged and sandy coastline, etc.)

- $\quad$ Local brand (Namahage as an important intangible cultural heritage)

- $\quad$ Variety of farm goods (rice, buckwheat noodle, melon, etc.)

- $\quad$ Safe and fresh foods, local cuisine

- Benignancy of the community

- $\quad$ Traditional event especially for rich harvest like festival

W (Weaknesses):

- $\quad$ Climate (strong sea winds)

- Population decrease

- $\quad$ Aging society

- $\quad$ Poor transportation facilities (only Oga train exists)

O (Opportunities):

- $\quad$ Gourmet-oriented, interests for food safety

- $\quad$ Increase of foreign tourists

- Word of mouth communication over SNS to spread local information $\mathrm{T}$ (Threats):

- $\quad$ Competition with neighboring areas for attracting visitors 
- $\quad$ Constraints by local governing body (e.g., subsidy)

- Consumption tax rise

The recent trend of visitors is shown in Table 1 . The number of lodgers has decreased from 2012 to 2014, while the number of day-trippers has been increasing. This might be related to the road improvement that has taken place around the Oga area. A comfortable drive can induce many day-trippers to visit these areas from nearby cities. However, visitors usually think that a short trip is enough. Therefore, the amount of per person spending has recently been decreasing.

Table 1: Trend of visitors [15]

\begin{tabular}{llll}
\hline & 2012 & 2013 & 2014 \\
\hline \hline Number of lodgers & 168,626 & 161,117 & 141,668 \\
Number of day-trippers & $1,904,345$ & $2,326,155$ & $2,718,886$ \\
& $2,072,971$ & $2,487,272$ & $2,860,554$ \\
Total number & $6,367,682$ & $7,311,105$ & $6,927,034$ \\
$\begin{array}{l}\text { Total amount of spending } \\
(1,000 \text { yen) }\end{array}$ & & & \\
Spending per person (yen) & 3,072 & 2,939 & 2,422 \\
\hline
\end{tabular}

\subsection{Sustainable framework of local revitalization}

According to the analysis based on previous discussions, we construct a framework for a sustainable local revitalization system applying the cause-effect relationship as shown in Figure 2. Although it takes a long time of revitalizing, the goal of local revitalization is to increase the number of permanent settlers and to provide sufficient jobs inside the area. It is firstly important to aware the land for many people. Therefore, increasing the number of visitors is the first target. If these visitors aware the land well, we try to make them repeat visitors as the next step. If the number of repeat visitors grows, they give effect on the other people by word-of-mouth and positive feedback will work for more visitors. Furthermore, the jobs related to sightseeing will be produced for taking care of huge amount of visitors. If the jobs are stable, some people are expected to come to work as permanent settlers as the final step. Thus, such feedback cycle is considered to be a sustainable local revitalization system in this study.

This study especially focuses on the first step, i.e., what the countermeasures are for increasing the number of visitors. 


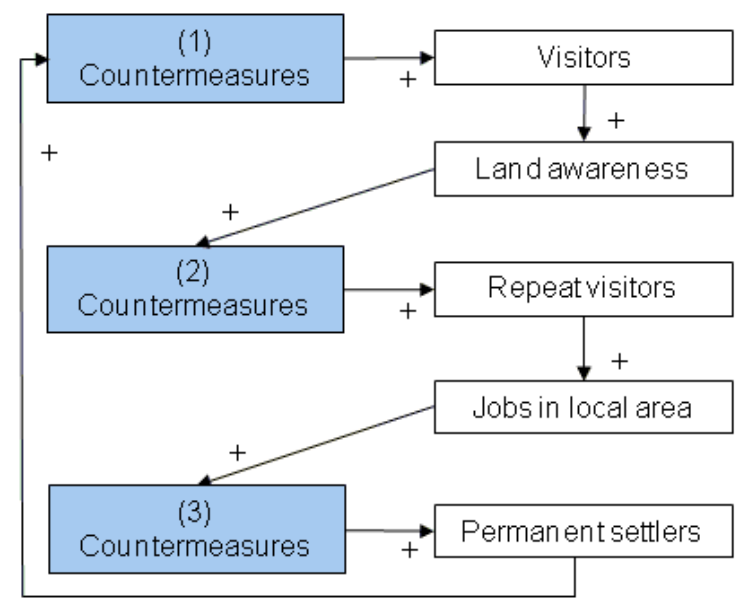

Figure 2: Sustainable framework for local revitalization

\subsection{Touring features of Oga city by text mining}

We first capture and analyze word-of-mouth information from visitors to determine their requirements. Text mining is used on 573 comments on TripAdvisor, which has been a well-known travel site for Oga City for about seven years. We used Text Mining Studio (TMS 5.2.1), provided by NTT DATA Mathematical Systems Inc. Term frequency is calculated as shown in Figure 3. "Namahage" which represents the messenger of God with goblin mask has the highest term frequency score. "Namahage museum" and "live performance" are related words. This is because live performance by Namahage at the museum is widely known to everybody in nationwide. In addition, the terms "sea”, "view," and "go" appear many times in the TripAdvisor reviews. Terms representing impressions, such as "good," "nice," and "enjoy," also appear often. Because the usual comments are for limited natural and museum resources, the aim of visitors is very simple. As their destination is only one place, it is difficult to visit there repeatedly. One potential long-term improvement may be to obtain a variety of comments for not only natural and museum resources, but also for other types of resources in order to establish a supply of sightseeing resources.

Table 2 shows the results of frequency of dependency parsing among 573 comments. The pairs "Namahage - live performance" and "view - nice" have the highest scores. It is evident that the results are related to the results of term frequency. Moreover, all the terms are deeply related to outdoor settings, such as "view," "go," "sea," "weather," etc. It is easy to understand that the panoramic view of the surrounding sea is a major attraction for all visitors. 


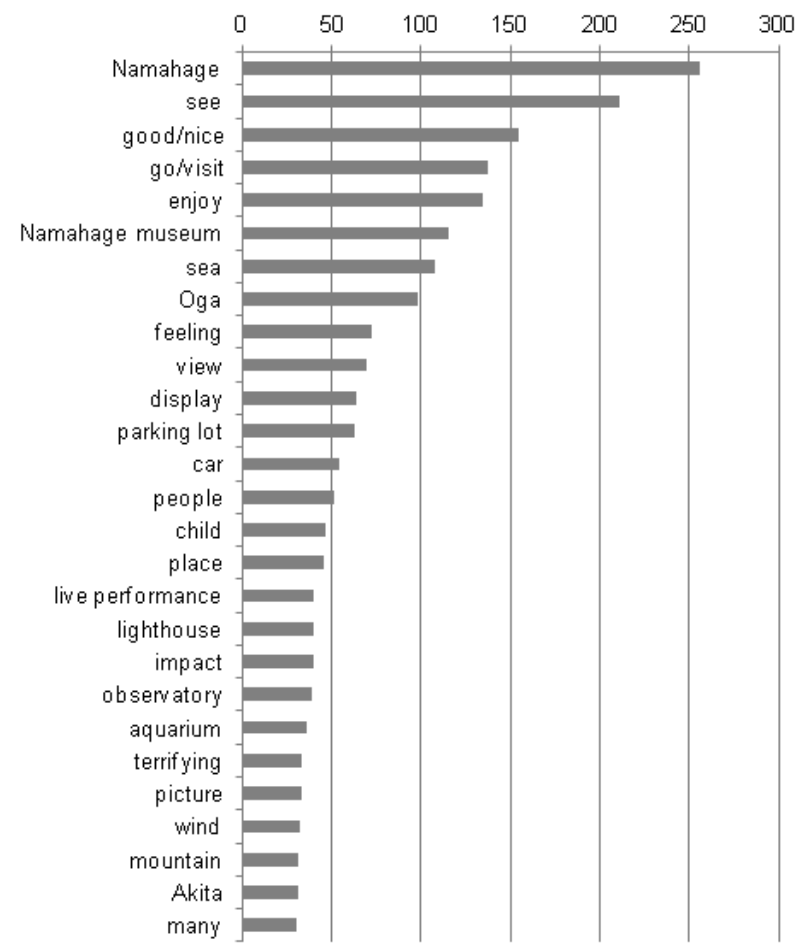

Figure 3: Term frequency

Table 2: Dependency parsing

\begin{tabular}{ll}
\hline Terms & Frequency \\
\hline \hline Namahage - live performance & 21 \\
View - nice & 21 \\
Weather - nice & 17 \\
Picture - taken & 17 \\
Namahage - display & 15 \\
Wind - strong & 14 \\
View - enjoy & 12 \\
Feel - good & 10 \\
Live performance - see & 8 \\
Next door - Namahage museum & 8 \\
Namahage - see & 7 \\
Dress - wear & 7 \\
View - see & 7 \\
See - go & 7 \\
Oga - go & 7 \\
\hline
\end{tabular}


We then examine whether a term reflects a good impression or bad one. Positive and negative scores for each term which we obtained by TMS 5.2.1 are shown in Figure 4. The highest positive score is predominantly for "view." Terms relating to natural resources and feelings are continuous. Almost all the comments have positive scores, while "footing," "road," and "staircase" have greater negative scores than positive ones. The meaning behind the negative presentation of these terms might be, for example, "be careful when driving the road to the mountain" if the road is narrow or winding. Another example might be "be careful when walking on the seashore," if it is difficult to walk on a slippery trail.

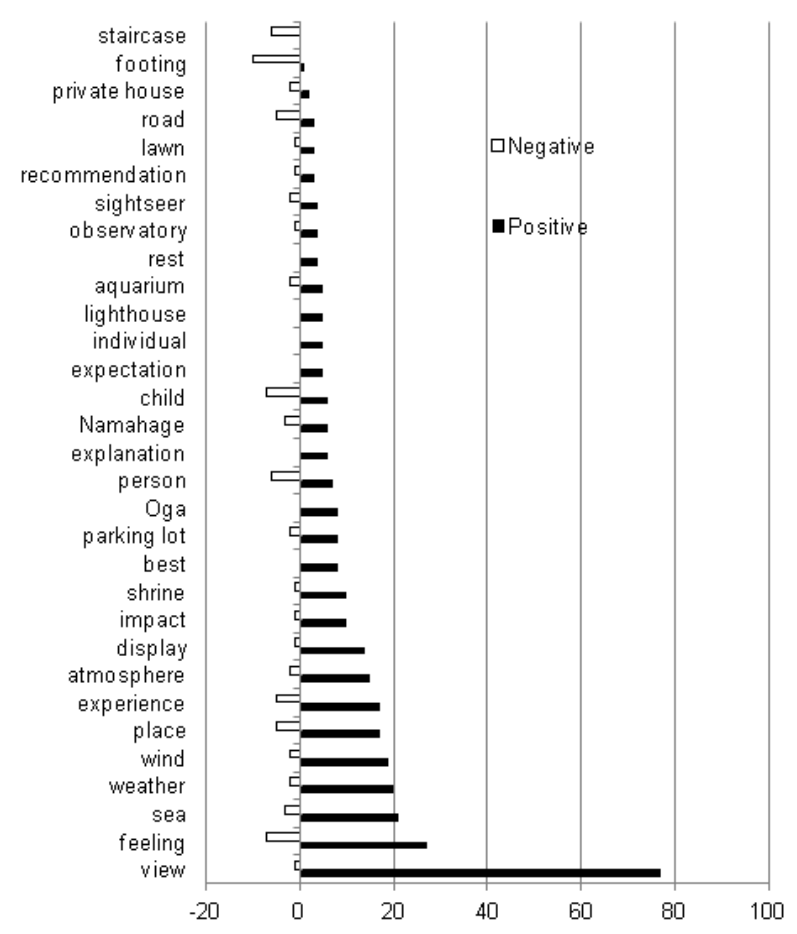

Figure 4: Positive and negative scores of terms

\subsection{Requirements for tourism}

By analyzing the terms obtained in the previous subsection, we construct a flow for tourism system, as shown in Figure 5. First, we list all the visiting resources, such as landscape/museum, food, and experience-based resources. The resource items are constantly updated through system feedback. The pleasure of a trip generally starts by making a tour plan. Because outsiders usually know little about local resources, the revitalization measure aims to interest people in these resources and to make tour planning easy. Therefore, we focus on providing itinerary alternatives for visitors to inspire them from the beginning. Some of the issues encountered include the shortage of parking lots, gaining access to transportation, and finding accommodation. Such applications or systems are widely used for activity promotion and PR. After using the application or system, feedback from visitors is collected by questionnaire and results are analyzed. We try to find ways to improve, and 
give feedback on the revitalization measure as PDCA (Plan-Do-Check-Action). Our study firstly focuses on providing itinerary alternatives for visitors.

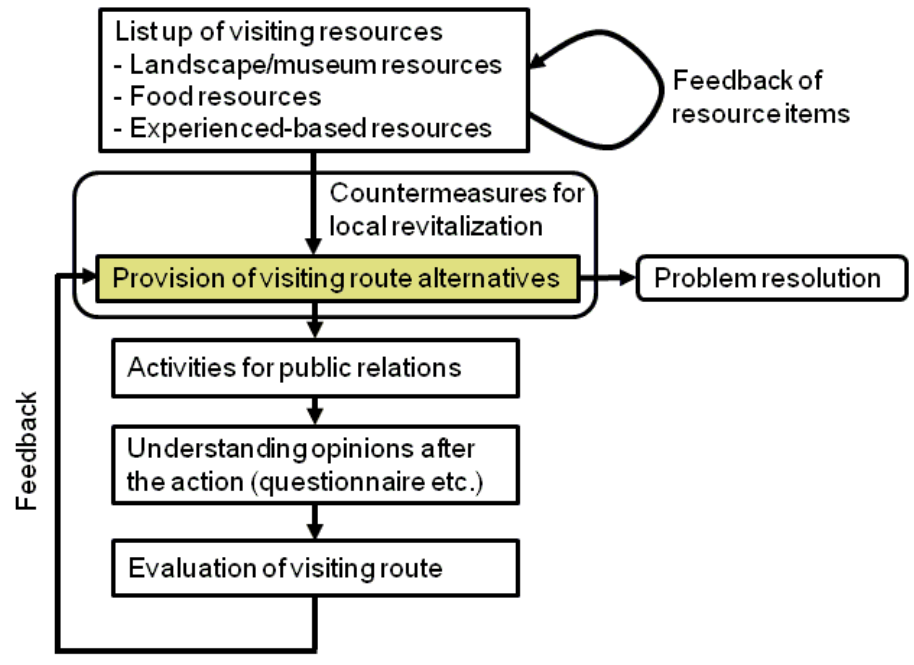

Figure 5: Flow for tourism system

By doing so, we expect that visitors will be satisfied with an enjoyable itinerary, trip efficiency, and positive feedback from their travelling party. Moreover, the ease of tour planning will bring visitors back.

Table 3: Requirements for sightseeing route decision steps

\begin{tabular}{lll}
\hline Stage & Goal & Requirements \\
\hline \hline 1: Basic planning & Plan feasibility & $\begin{array}{l}\text { Many route alternatives } \\
\text { with recommendation }\end{array}$ \\
2: Detail planning & Itinerary and expenditure & $\begin{array}{l}\text { Many route alternatives } \\
\text { with estimation of time } \\
\text { and cost }\end{array}$ \\
3: Trip preparation & Reconfirm schedule & $\begin{array}{l}\text { Precise times for visiting } \\
\text { and transportation }\end{array}$ \\
4: Travel & $\begin{array}{l}\text { Find a suitable route } \\
\text { when change is required }\end{array}$ & $\begin{array}{l}\text { Quick alternative route } \\
\text { calculation }\end{array}$ \\
\hline
\end{tabular}

Next, we consider visitors' actions from the planning stage to the execution stage of the trip. There are many itinerary alternatives for visitors. The requirements for deciding the sightseeing route are then considered, as shown in Table 3. There are generally four stages in the sightseeing route decision. The role of the first planning stage is to ensure the plan is feasible. Many people expect recommendations for several route alternatives so that they can make flexible plans. The second stage is detail planning. The goal of this stage is to decide the 
itinerary and the budget. In this stage, people want to know more precisely how much time and money to spend. The third stage is trip preparation. The aim of this stage is to reconfirm the schedule. People want to know the precise times for visiting resources, train timetable, etc., before they go. The fourth stage is the travel stage. It often happens that the selected travel route must be changed because of weather, health, money, etc. Therefore, we need a quick alternative route calculation function.

\section{Formalization of recommend route}

Let us formalize the requirements discussed in the previous section in order to develop a tour planning support system.

\subsection{Input condition}

In order to construct a system, we first define the input information for each stage. Input items are extracted according to the goal of the stage and its requirements. The input items are shown in Table 4. These items are days of visit, start and end places, staying places, visiting places, transportation, active time, budget, and visiting order, using [11] as a reference. Input items are either compulsory or arbitrary for each stage. Days of visit is defined as how many days the visitor spends on the trip. Start place means the location where the visitor starts his/her trip. That includes not only his/her house but also the place near the target area for his/her trip. End place means the end location where visitor ends his/her trip. That includes not only his/her house but also the place near the target area. Staying places means the place where the visitor stays, such as hotel, inn, etc. In addition to these places, visiting places are also a compulsory input item for the basic planning, detail planning, and trip preparation stages. Transportation is the means of movement, such as train, car, bus, etc. This condition is only compulsory at the trip preparation stage. This is because the precise timetable and visiting order are required at this stage. Active time means the hours available for visiting in a day. Although this input is not required, it is needed in order to decide the number of visiting places per day. Budget and visiting order become compulsory inputs for the detail planning and trip preparation stages.

Table 4: Input conditions

\begin{tabular}{lllll}
\hline Input & $\begin{array}{l}\text { Basic plan- } \\
\text { ning }\end{array}$ & $\begin{array}{l}\text { Detail plan- } \\
\text { ning }\end{array}$ & $\begin{array}{l}\text { Trip prepa- } \\
\text { ration }\end{array}$ & Travel \\
\hline \hline $\begin{array}{l}\text { Days of visit } \\
\text { Start and } \\
\text { end places }\end{array}$ & Compulsory & Compulsory & Compulsory & Arbitrary \\
$\begin{array}{l}\text { Staying } \\
\text { places }\end{array}$ & Compulsory & Compulsory & Compulsory & Compulsory \\
$\begin{array}{l}\text { Visiting } \\
\text { places }\end{array}$ & Compulsory & Compulsory & Compulsory & Arbitrary \\
$\begin{array}{l}\text { Transporta- } \\
\text { tion }\end{array}$ & Arbitrary & Arbitrary & Compulsory & Arbitrary \\
Active time & Compulsory & Compulsory & Compulsory & Compulsory
\end{tabular}




\begin{tabular}{lllll} 
Budget & Arbitrary & Compulsory & Compulsory & Arbitrary \\
$\begin{array}{l}\text { Visiting } \\
\text { order }\end{array}$ & Arbitrary & Arbitrary & Compulsory & Arbitrary \\
\hline
\end{tabular}

\subsection{Network model}

The purpose of defining network model is to calculate recommend route alternatives for users. Regional resources and the routes between them are presented as a network model in Figure 6. The node set $N$, which corresponds to regional resources, includes $n_{0}$ (start place), $n_{k}$ (end place), and $n_{s}$ (staying place). Visiting places are included in $N_{v}(\subset N)$ and represented as $\left\{n_{i}\right\}$ where $i=$ 0 to $k$. Furthermore, regional resources also belong to the set $N N_{v}$ which the visitor does not select as a place to visit at first. These nodes are needed for constructing network model for three stages except travel stage, this is because visitor cannot make plan without these nodes. The link set $L$ contains $\left\{l_{i j}\right\}$, which can exist as multi-links as shown in Figure 6. Setting multi links are necessary especially in trip preparation stage, this is because a visitor selects means of movement precisely with considering active time. All nodes have a classification type as an attribute, such as natural/museum, food, and experience-based resources. Although we can verify the node type, nodes are not classified for constructing recommended routes as an input condition in order to provide flexibility for users.

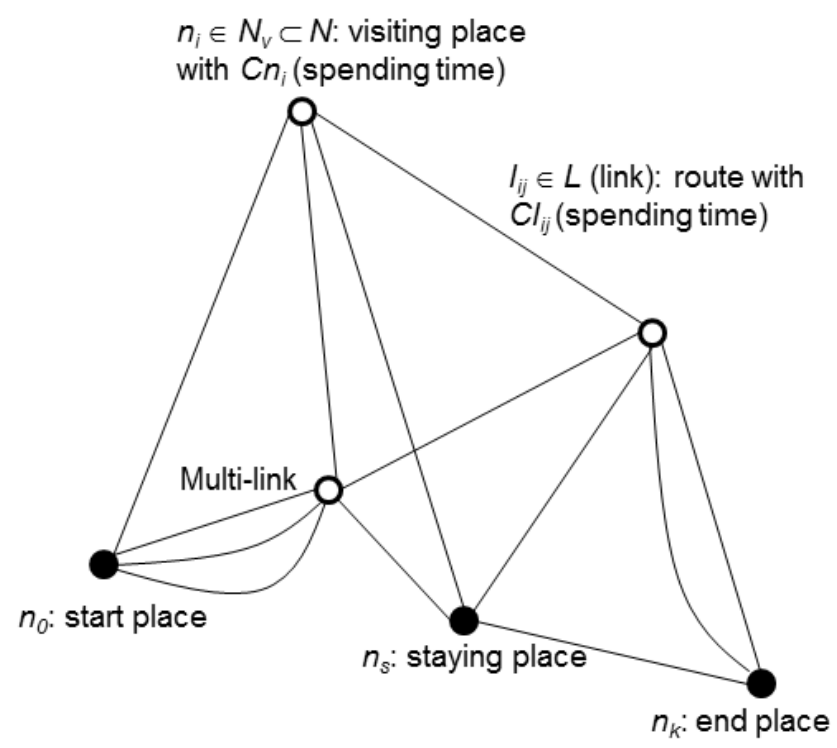

Figure 6: Network model

In order to calculate and select the shortest route between start and end places, spending time of a node $\left(C_{i}\right)$ and spending time of a link $\left(C l_{i j}\right)$ are given as the set of $C_{N}$ and $C_{L}$, respectively.

\section{System architecture}

Tour planning support systems are discussed in this section. We first focus on a system architecture that maintains function flexibility and expandability for the future. Figure 7 shows the 
system architecture of a tour planning support system. It has three components: input, calculation, and output. Input includes resource classification, time schedule planning, and selection of visiting site as functions. Resource classification is easily linked to each resource information website by hyperlinks so users can easily find places of interest (POIs). Moreover, time schedule planning is also connected to transportation websites such as JR, ANA, and JAL. Users can select visiting places easily by using the selection of visiting site function.

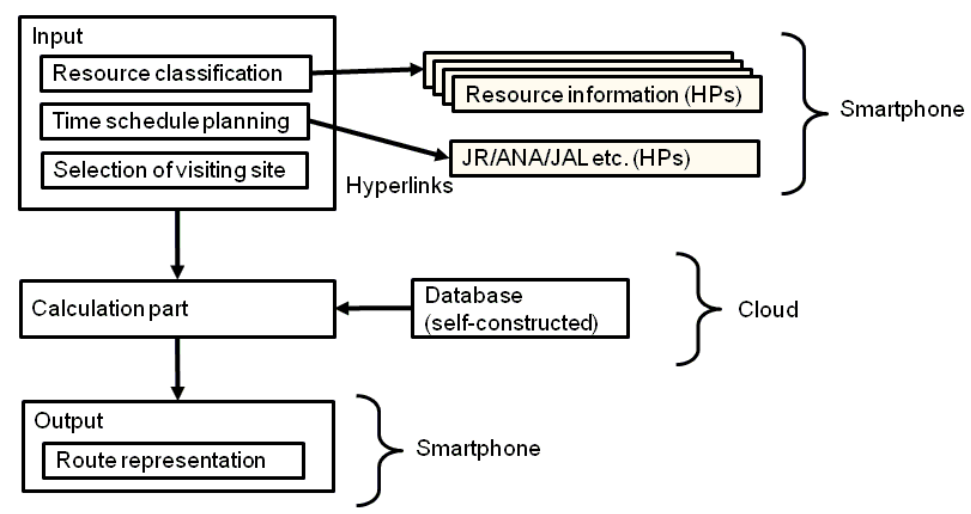

Figure 7: Tour planning support system

The architecture for the calculation component is described later, but this function is based on a self-constructed database. That is to say, the network model described in the previous section is the preliminary input. Because the size of the prepared database is large, and quick calculation is needed, a calculation component based on a database is suitable for the cloud environment.

The output component shows several alternative routes for a user. It is essential that the result is shown on a Google map. Moreover, the user can modify the plan and easily give feedback to the input component. Because creating a tour plan with smartphone is convenient for visitors, it is necessary to adapt the input and output components for a smartphone.

The calculation component involves at least two major functions, the recommend route planning function and the interactive conversation function. The algorithm for these functions is shown in Figure 8 as an architecture. The input is the graph $G=\left(N, L, C_{N}, C_{L}\right)$, where $N$ is a set of nodes, $L$ is a set of links, $C_{N}$ is a set of costs of nodes and $C_{L}$ is a set of costs of links, respectively. $N_{v}$ is a subset of $N$, which includes visiting resources. Specifically, $n_{0}$ is a starting point of a trip, $n_{k}$ is an ending point of a trip, and $n_{s}$ is a staying point of a trip. We assume a one-day trip or a two-day trip in this paper. Hence, $X$, a day of visit, is an input, in addition to $T$, active time in a day.

The proposed system architecture has three features. The first feature is the calculation of the shortest route function from source to destination based on the Dijkstra algorithm [13] or a Traveling Salesman Problem algorithm [14]. The algorithm used depends on the condition of the source and the destination. The second feature is the grouping of nodes for each day, especially in the case of a two-day trip. The grouping is based on an algorithm to implement a Voronoi diagram [15], or a plane sweep algorithm as a heuristic [16], depending on the condition of the source and the destination. $C_{R}(i-j)$ denotes the cost of the route from node $i$ to node $j$. The third feature is the iteration of the afore-mentioned algorithms for nodes with the operation between $N_{v}$ and $N \backslash N_{v}$. This function supports interactive conversation with users to make a satisfactory plan. 


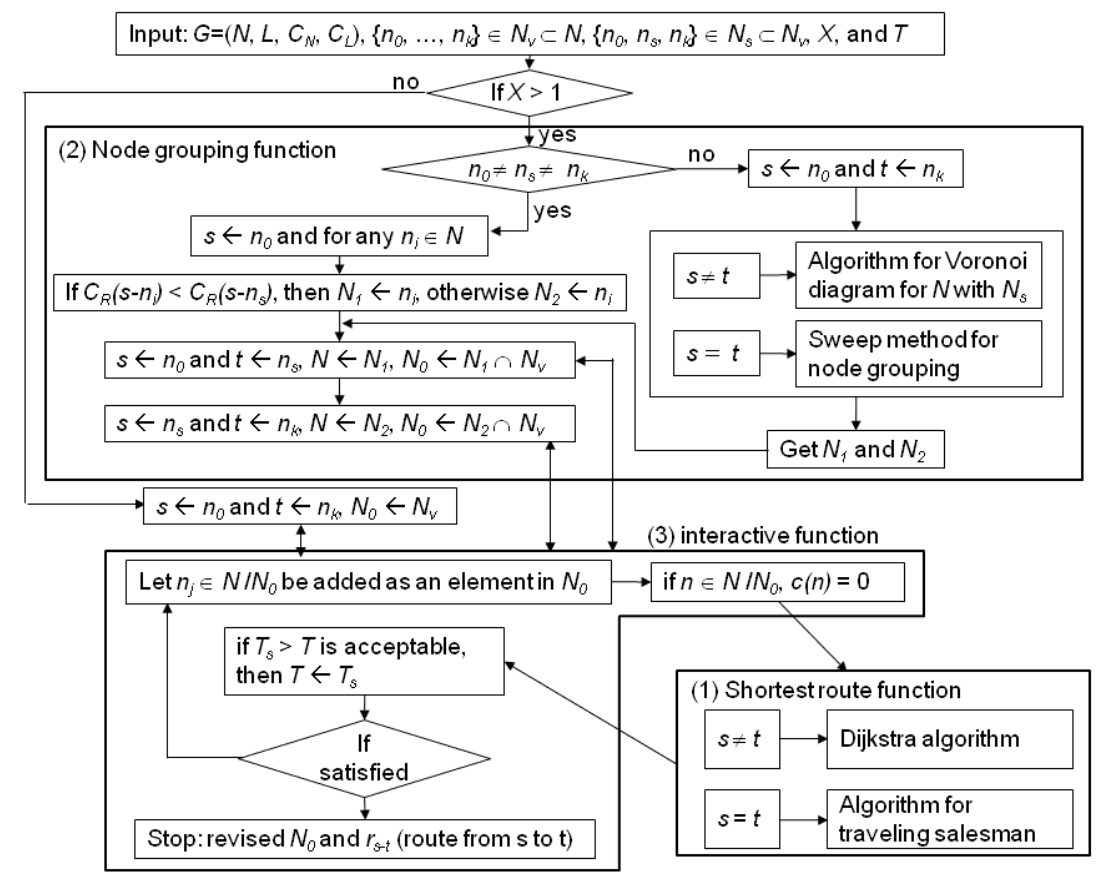

Figure 8: Architecture of the calculation component

\section{Conclusion}

The problem of an aging society can occur almost anywhere, and the problems caused by such a situation are worst in rural areas. Therefore, there are many rural areas where local revitalization is needed. One of the key solutions is to discover the factors involved in continuous revitalization.

Our study aims to propose continuous support systems in order to revitalize local areas through tourism. This paper first focuses on the requirements of local revitalization and constructs a framework for a sustainable system. It is very difficult for strangers to create an itinerary of unfamiliar places efficiently. A tour planning support system architecture which contains network model and algorithms from basic planning to the travel stage is proposed as a measure for revitalization.

Future study lies on the assessment of network models and algorithms through some cases. At first, we have to develop the proposed system including human interface with considering users' requirements. It is necessary to use it continuously so that we can evaluate the system quantitatively.

\section{References}

[1] Ministry of Internal Affairs and Communications, "Long-term changes in population in Japan,” Dec. 2017: http://www.soumu.go.jp/main_content/000273900.pdf.

[2] Ministry of Agriculture, Forestry and Fisheries, "Current state and countermeasures for denuded farmland,” Dec. 2017: http://www.maff.go.jp/j/nousin/tikei/houkiti/attach/pdf/index-4. pdf. 
[3] A. Sawada, H. Horii, M. Horii, M. Hayashi, M. Yoneda, and T. Yoshida, "KuKuRI: Proposal for information system to support endogenous tourism development,” Jpn. Soc. Manag. Info. (JASMIN), 2010, pp. 17.

[4] M. Kawasaki, "A study on utilization of Michinoeki roadside parking station," Master thesis of Kochi University of Technology, 2014.

[5] Y. Koyama, ”Sightseeing and peninsula promotion,” Land Inst. Jpn., vol. 19, no. 4, 2011, pp. 21-39.

[6] J. Kobayashi, A. Soshiroda, H. Takei, and T. Miura, "A study on products of destination-based tourism with regional resources produced by $3^{\text {rd }}$-class travel,” J. Jpn. Inst. Tour. Res., Tour. Stud., vol. 23, no. 1, 2011, pp. 39-47.

[7] P. Checkland and J. Scholes, Soft Systems Methodology in Action, John Wiley \& Sons, 1990.

[8] M. Iwashita and S. Kato, "Local Revitalization Model Based on Soft Systems Methodology," Proc. IEEE/ICIS2016, 2016, p. 1007-1012.

[9] T. Hara et al., Introduction to Tourism Informatics (in Japanese), Kindai Kagakusya Co. Ltd., 2015.

[10] J. Borras, A. Moreno, and A. Vallas, "Intelligent tourism recommender systems: A survey," Expert Systems with Applications, vol. 41, no. 16, 2014, pp. 7370-7389.

[11] U. Gretzel, "Intelligent systems in tourism: A social science perspective,” Annals of Tourism Research, vol. 38, no. 3, 2011, pp. 757-779.

[12] P. Vansteenwegen and W. Souffriau, "Trip planning functionalities: State-of-the-art and future,” Information Technology and Tourism, vol. 12, no. 4, 2011, pp. 305-315.

[13] P. Vansteenwegen, W. Souffriau, G. V. Berghe, and D. V. Oudheusden, ”The City Trip Planner: An expert system for tourism,” Expert Systems with Applications, vol. 38, no. 6, 2011, pp. 6540-6546.

[14] T. Hara, "Tourism Informatics and Tour Planning Services Toward Tokyo Olympics and Paralympics 2020,” Journal of the Japanese Society for Artificial Intelligence, vol. 31, no. 6, 2016, pp. 858-863.

[13] E. W. Dijkstra, "A note on two problems in connexion with graphs," Numerische Mathematik, vol. 1, 1959, pp. 269-271.

[14] C. Rego, D. Gamboa, F. Glover, and C. Osterman, ”Traveling salesman problem heuristics: leading methods, implementations and latest advances,” European Journal of Operational Research, vol. 211, no. 3, 2011, pp. 427-441.

[15] Oga City Hall, “Tourism statistics,” Dec. 2017: http://www.city.oga.akita.jp/index.cfm/12, 15817,c,html/15817/20170630-143643.pdf.

[16] D. F. Watson, ”Computing the n-dimensional Delaunay tessellation with application to 
Voronoi polytopes,” Comput. J., vol. 24, no. 2, 1981, pp. 167-172.

[17] B. E. Gillet and L. R. Miller, "A heuristic algorithm for the vehicle dispatch problem,” Operations Research, vol. 2, 1971, pp. 340-350. 